of the endocrines on the nervous system and behaviour, and more recently the influence of the nervous system on endocrine function, have been known in a general way to those engaged in medical practice for many years. The deliberate experimental study of the extent and mechanism of these interrelationships is a more recent development. Of the influence of hormones on behaviour, still very little is known except in certain limited fields. The studies of Beach on the modification of animal behaviour under the influence of sex hormones are outstanding in this field. Nervous control of the endocrine glands has been more extensively studied and more is known of this.

Despite the fact that only two endocrine glands the adrenal medulla and the posterior pituitary-are known to have an anatomically obvious and functionally important direct nerve supply, nervous factors are known to play an important part in endocrine function. Marshall's original investigations on the importance of "exteroceptive factors", such as light and temperature, on the sex rhythms of lower animals, have been confirmed and extended in great detail. More recently the responses of the adrenal cortex under the control of the adrenocorticotrophic hormone of the anterior pituitary have been exhaustively studied. An animal exposed to physical or chemical trauma, or to various procedures such as forced immobilization or loud noises, all presumed to cause mental disturbance and, for want of a more precise term, grouped together as 'emotional stresses', exhibits definite signs of increased adrenal cortical activity. Recent work in Prof. Harris's laboratory seerms to indicate that in rabbits the activity of the thyroid gland, under the control of pituitary thyrotrophic hormone, decreases in response to such 'stresses' that are known to activate the suprarenal gland. The clinical impression that emotional disturbance may be a precipitating factor in the onset: of human hyperthyroidism is another indication of nervous influence on thyroid function.

There is, therefore, a very considerable body of evidence, from many sources, of nervous and mental influence on endocrine function, mediated mainly via variations in the output of the trophic hormones of the anterior pituitary gland.

The discussion at the meeting centred mainly on the influence of psychological factors on endocrine function. Various speakers commented on the difference in response of the experimental animal and man with respect to thyroid function. Prof. Harris replied that the depression seen in his animals was unexpected in view of the information available about human disease. A species difference was postulated by other members of the audience. Different responses in the same species to similar physical stress accompanied by presumably different emotional states were described; in the ritual fighting of male mice kept together, the blood sugar of the aggressor is elevated, but not that of the attacked animal, though both exhibit violent physical activity.

Dr. Parkes, in his summing-up, re-emphasized the importance of the approach discussed by Profs. Roche and Young-the detailed study of the mechanism of peripheral action of the hormones. For the non-chemical endocrinologist, perhaps the most valuable and promising field for future research is the influence that the external environment, acting through the central nervous system, exerts upon the endocrine state of the organism.

\section{ANALYSIS OF MECHANICAL AND ELECTRICAL ENGINEERING FAILURES}

\begin{abstract}
B EFORE the Second World War the British Engine $B$ Boiler and Electrical Insurance Co., Ltd., issued annually a technical report dealing both with original work and with the investigation of engineering failures. Vol. I of a new series has just been published, which more than maintains the high standard of its predecessors*. This publication will be found to be of the very greatest interest by all engineers and metallurgists who are concerned with the field common to the two professions.
\end{abstract}

The first forty-five pages are devoted to a most commendable discussion from the practical point of view of caustic cracking in steam boilers, possibly the most comprehensive treatment which has so far appeared. A very considerable number of cases are discussed in detail, and since neither chemists nor metallurgists are as yet in complete agreement as to the details of the fundamental mechanism involved, and since no reliable means of preventing this dangerous form of deterioration has been developed, these are the more valuable. It is suggested that the best advice that can be offered in the light of present knowledge is that the workmanship of new boilers should be of a high standard, particularly as regards the sealing of the riveted seams on the water side; that care should be taken to avoid over-heating, rapid fluctuations of temperature, and other factors arising under working conditions which may disturb the seams; that special care is required in repair work in connexion with the sealing of such seams; and the maintenance of a minimum caustic alkalinity of the boiler water and the maintenance of a sodium sulphate/sodium hydroxide ratio above $2 \cdot 5$.

A most interesting account by Mr. G. A. Cottell of original work on the sources of error in notched-bar testing concludes this publication. The apparatus is described and the sources of error carefully differentiated; in particular, the influence of the seat between the specimen and the machine has been investigated and a new form suggested which cuts down the loss very considerably and, at the same time, eliminates much of the scatter found under normal conditions. It is shown that the results of such losses may reach as high a value as 25 per cent. It is of more than a little interest that, when using a modified form of specimen or a modified type of test, the yield point is clearly shown, even under notched-bar conditions. A fact of great interest which emerges from this work is the evidence that the speed of fracture exerts a considerable influence on the results. A comparison is made between impact and slow-bend tests on identical specimens, and it is shown that the total work of fracture with the Izod specimen is almost 20 per cent higher in impact than when the specimen is broken slowly. A continuation of this work will be looked for by many.

The remainder of the report is concerned with the examination of twenty-seven cases of service failure, a typical one being that of the brittle fracture of a crane hook, which is referred to strain age-embrittlement in a rimming steel, resulting from the strain and heating due to compression and abrasion. A similar example of strain age-embrittlement in a * British Engine Boiler and Electrical Insurance Co., Ltd. 'Technical Report, New Series, Vol. 1. Pp. 212. (From the Company, 
rimming steel occurred in the case of some boiler rivets, the brittleness being traced to the presence of nitride 'needles'. Such work is in a direct line with the tradition in these reports, since Stromeyer's work on the effect of nitrogen in embrittling steel was carried out in the laboratories of the Manchester Steam Users' Association, now taken over by the Company which has issued this report. Incidentally, the same tradition can be traced in the work on the notched-bar test, a subject on which Schuster carried out considerable research.

The account of these investigations on engineering parts which have failed is very welcome. Only too often, service failures are hidden in the scrap heap, and careful investigation can be of immense value in minimizing the danger of further fractures from the same cause. These investigations cover both the mechanical and electrical fields. In the latter there is also an article by D. C. Bacon on "Excess Current Protection of Electric Motor Circuits". Among the failures which are reported are those due to the cracking of a riveted seam due to excess riveting pressure, tube failures, butt-welded joints, failure of turbine blades and shaft, fracture of a steam engine crank-shaft, an accident to an electric goods-lift, defective squirrel-cage motor-rotors, the disruption of a hydro-extractor, and the explosion of an air vessel. In all, these reports provide a very considerable amount of information which should be of value both in design and in the maintenance of mechanical and electrical equipment.

The presentation of this work is more than good, the illustrations and micrographs are excellent, and at the low price at which it is issued should appeal to a very wide range of readers.

F. C. THOMPSON

\section{UNIVERSITY OF WITTENBERG (I502-1952)}

$\mathrm{T}$ HE Martin-Luther University of Halle-Witten berg, in the East Zone of Germany, held a celebration during October 18-25, 1952, to mark the four hundred and fiftieth anniversary of its foundation at Wittenberg, nearly two hundred years before the separate foundation of the University at Halle, with which it was merged on reopening in 1815 after being closed in 1813 by Napoleon. The pro-rector, Prof. Leo Stern, acted for the rector, Prof. Rudolf Agricola, who was absent through illness. The following details are given in a letter from one of the West Zone delegates.

The opening ceremony was in the Theatre of Peace at Halle. A colourful scene was provided by the university professors, deans, pro-rectors and rectors in their robes. The celebration on Sunday, October 19, took place in the town church of Wittenberg; Prof. Aland gave the address, and at a church service in the afternoon the sermon was preached by Bishop Dibelius. The ceremony was attended by Hungarian and Roumanian bishops, by a representative of the Chinese Christian Reform Movement, and by the Rev. Edward Charles, from Great Britain. On October 20 there was a function, at which scientific addresses were given, at the Institute for German History, a student youth demonstration in the market, and musical performances (Handel, Bach, Brahms and others). On the following day a special meeting of the Leopoldina Academy was held, with lectures and demonstrations on the theme "Der schwerhörige Mensch". The birthplace of the Leopoldina Academy-Schweinfurt in the West Zone of Germany-was officially represented by its mayor, Dr. O. Schön, and by Dr. J. Helfrich, who had already represented his town at Halle for the tercentenary of the Leopoldina Academy in February 1952 (see Nature, 169, 576, and 170, 1105; 1952), and they were most warmly received. There followed numerous parallel sittings of the different faculties, with exhibitions. Receptions were held by members of the East Zone Government, by the regional and civic authorities and by the University Senate, and a performance was given of Handel's opera "Tamerlano". R. C. H. Youna

\section{FORESTRY RESEARCH AND ORGANIZATION}

TWO papers read at the Sixth British Commonwealth Forestry Conference, held in Canada last year, and now published by the Forestry Commission (London: H.M.S.O., 1952), deserve to be more widely noticed for the scientific importance of their message. The first was by Mr. J. N. R. Jeffers, of the Forestry Commission, London, who discussed the use of statistical methods in forest research. "To-day," he said, "the handling of figures has become a necessity; they are required for administration, management and research, and their collection, analysis and interpretation have become part of the forester's everyday work." The functions of these methods are to provide a sound basis for the design of experiments, to summarize data so that they can be correctly and readily interpreted, and to give an estimate of the probability that the effects indicated by the results are true effects. Statistical methods have become indispensable tools of forest research. It is now a question of making more foresters familiar with them and of asking statisticians to develop new methods when the existing ones are inadequate.

It may be pointed out, in passing, that this is more applicable to the research officer, for the forester's everyday work is, or should be, out in the forests and woods studying the methods of growth and well-being of his trees and their several requirements from the practical sylvicultural point of view on the ground. His job is to produce the timber, etc., of the future by practical sylvieulture and constant supervision on the ground. Statistics, though necessary, will not do this.

The other paper was by Mr. N. V. Brasnett, on the "Organization of Sustained Yield in previously Unmanaged Forests". He stated: "For periods within the physical rotations of the species which comprise them, mature, unmanaged forests can be assumed to be in state of dynamic equilibrium. Large old trees are generally in excess of mediumsized and small trees of the same species, which only have an opportunity of entering the top canopy as overmature trees die. Because no increment is harvested, it has slowed down until it is practically balanced by decay. The smaller trees are not all necessarily younger than the large ones, but may merely be suppressed and even capable of responding to release. Abundant seedlings are liable to appear on the forest floor in most years, but most of them fade away in a few years, leaving only individuals to survive in gaps here and there". The British have 